\title{
Türkçe Duruş Tespit Analizi
}

\author{
Kaan Kemal Polat ${ }^{1 *}$, Nilgün Güler Bayazıt ${ }^{2}$, Olcay Taner Yıldız ${ }^{3}$ \\ ${ }^{1}$ Yıldız Teknik Üniversitesi, Kimya Metalurji Fakültesi, Matematik Mühendisliği Bölümü, İstanbul, Türkiye (ORCID: 0000-0002-5472-8297), kemalp@yildiz.edu.tr \\ ${ }^{2}$ Yıldız Teknik Üniversitesi, Kimya Metalurji Fakültesi, Matematik Mühendisliği Bölümü, İstanbul, Türkiye (ORCID: 0000-0003-0221-294X), guler@yildiz.edu.tr \\ ${ }^{3}$ Özyeğin Üniversitesi, Mühendislik Fakültesi, Bilgisayar Mühendisliği Bölümü, İstanbul, Türkiye (ORCID: 0000-0001-5838-4615), olcay.yildiz@ozyegin.edu.tr
}

(İlk Geliş Tarihi 31 Aralık 2020 ve Kabul Tarihi 12 Mart 2021)

(DOI: 10.31590 /ejosat.851584)

ATIF/REFERENCE: Polat, K. K., Güler Bayazıt, N., \& Yıldız, O. T. (2021). Türkçe Duruş Tespit Analizi. Avrupa Bilim ve Teknoloji Dergisi, (23), 99-107.

\section{$\ddot{\mathbf{O} z}$}

İnternet kullanımının yaygınlaşmasıyla birlikte insanlar düşüncelerini, o anki duygu durumlarını sosyal medya araçları ve çevrimiçi forumlar üzerinden paylaşmaya başladılar. Bu durum metin verilerinin miktarında büyük bir artışa neden oldu. Başta Twitter platformundan elde edilen veriler olmak üzere sosyal medya kaynaklı veriler duygu analizi, metin sinıflandırma, konu modelleme, ironi tespiti, görüş madenciliği gibi pek çok çalışmada kullanılmaktadır. Bu çalışmalardan biri de duruş tespitidir. Duruş tespiti, bir hedefyorum çifti için yorum yazarının hedefe yönelik duruşunun yorum metninden otomatik olarak çıarılması işlemidir. Burada hedef bir insan, olay, durum veya bir ürün olabilir. Duruş tespitinde amaç bir yorumun sahibinin belirli bir hedefe yönelik duruşunun "Destekliyor" / "Desteklemiyor" / "Duruş Yok" olarak sınıflandırılmasıdır. Türkçe dilinde duruş tespiti çalışmalarında kullanılmak üzere hazırlanmış kapsamlı bir veri kümesi bildiğimiz kadarıyla bulunmamaktadır. Çalışmada ilk olarak bir çevrimiçi forumdan veri kazıma yöntemi ile 6 hedef için toplanmış yorumlardan oluşan bir Türkçe Duruş Veri Seti oluşturulmuştur. Veri seti toplam 5031 hedef-yorum çiftinden oluşmaktadır. Her bir hedef-yorum çifti üniversite dil bölümü mezunu kişilerce etiketlenmiş̧tir. Veri seti üzerinde Naive Bayes, Destek Vektör Makinesi, AdaBoost, XGBoost, Rastgele Orman ve Evrişimli Sinir Ağı yöntemleri ile duruş tespit analizi yapılarak sonuçlar paylaşılmıştır. Metin temsili olarak sözcük torbası, terim frekansı - ters doküman frekansı ve kelime gömme yöntemleri kullanılmıştır. Performans değerlendirmesinde Matthews Korelasyon Katsayısı kullanılmıştır. Yapılan deneylerde en iyi sonuçların XGBoost ve Evrişimli Sinir Ağı yöntemleri ile elde edildiği gözlemlenmiştir. Oluşturulan Evrişimli Sinir Ağı modelinden çıkartılan özniteliklere entegre grandyanlar yöntemi uygulanarak girdi verilerindeki özniteliklerin model tahminine katkıları incelenmiş; yazılan bir yorumdaki her kelimenin modelin tahminine katkısı görselleştirilerek örneklerle sunulmuştur.

Anahtar Kelimeler: Duruş Tespiti, Metin Madenciliği, Destek Vektör Makinesi, Kolektif Öğrenme.

\section{Turkish Stance Detection Analysis}

\begin{abstract}
With the widespread use of internet, people began to share their thoughts and their current moods through social media platforms and online forums. This led to a larger increase in the amount of generated text data. Data from social media, especially data obtained from Twitter, are used in many studies such as sentiment analysis, text classification, topic modelling, irony detection, opinion mining. One of these is stance detection. Stance detection is the process of automatically extracting the stance of a person commenting on a text from a target-comment pair. Here the target can be a person, event, case or a product. In stance detection, the purpose is to classify the stance of the commenting person as "Favor" / "Against" / "Neither". As far as we know, there is no comprehensive dataset ready for use in stance detection studies in the Turkish language. The first contribution of the current work is the creation of a Turkish Stance Dataset consisting of comments collected for 6 targets by web scraping from an online forum. The dataset consists of a total of 5031 targetcomment pairs. Each target-comment pair has been tagged by Language Department graduates. The Bag of Words, Term Frequency Inverse Document Frequency and Word embedding methods have been used for text representation. The analysis of the results for stance detection based on Naive Bayes, Support Vector Machine, AdaBoost, XGBoost, Random Forest and Convolution Neural Networks methods are presented. Matthews Correlation Coefficient has been used for performance assessment. It has been observed that the best results have been obtained with the XGBoost and Convolutional Neural Network methods. By applying the integrated
\end{abstract}

* Sorumlu Yazar: kemalp@yildiz.edu.tr 
gradients method to the features extracted by the Convolutional Neural Network model, the contribution of the features input to this method to the prediction performance has been analyzed and the contribution of each word in a comment to the prediction performance has been presented by visual examples.

Keywords: Stance Detection, Text Mining, Support Vector Machine, Ensemble Learning.

\section{Giriş}

Günümüzde dijital iletişim araçları, insanlar tarafindan yaygın olarak kullanılmaktadır. $\mathrm{Bu}$ dijital iletişim araçlarına forumlar, bloglar, çeşitli yayın platformları, Facebook, Instagram ve Twitter örnek olarak verilebilir. İnsanların sosyal yaşantılarında çok fazla yer tutar hale gelen bu iletişim araçları, çeşitli amaçlar için analiz edilebilir büyük miktarda metinsel verinin toplanmasına katkı sağlamaktadır. Toplanan bu dijital verilerden otomatik bilgi çıkarmanın önemi de giderek artmaktadır. $\mathrm{Bu}$ sebeple metinsel verilerin işlenmesine yönelik çalışmalara gösterilen ilgi de son yıllarda giderek artmıştır. Duygu analizi, metin sınıflandırma, konu modelleme, ironi tespiti, görüş madenciliği gibi çalışmalar, metin madenciliği için popüler araştırma konularıdır. Bu konular arasında son yıllarda duruş tespiti çalışmaları da önemli şekilde yer almıştır. Duruş tespiti çalışmalarının sayısının artmasının sebebi dijitalleşmenin insan hayatında artması ile insanların belirli bir konu/nesne/kişi hakkında tutumlarının belirlenebileceği metinsel verileri üretmeleri, duruş tespitinin sahte haber tespitinin ilk adımı için önemli bir aşama olabileceği fikri ve duruş tespiti ile ilgili çeşitli yarışmaların yapılmasıdır (S. Mohammad et al., 2016; Taulé et al., 2017; R. Xu et al., 2016).

Duruş ile ilgili çalışmalar incelendiğinde birbirine yakın çeşitli tanımlar yapılmıştır. $\mathrm{Bu}$ tanımlar arasından en kapsamlı olanı bir dilbilimci olan John W. Du Bois tarafından yapılmıştır. Du Bois'e göre "Duruş sosyokültürel alanın herhangi bir göze çarpan boyutuna göre nesneleri eşzamanlı olarak değerlendirme, özneyi (benlik ve diğerleri) konumlandırma ve diğer konulara hizalama yoluyla açık iletişim araçlarıyla diyolojik olarak gerçekleştiren bir sosyal aktör tarafından gerçekleştirilen kamusal bir eylemdir. "(Du Bois, 2007). Bu tanımdan yola çıkarak duruş için bir kişinin belirli bir hedefle ilgili bakış açısı, görüşü veya yargısı diyebiliriz.

Duruş Tespiti, bir metin parçası ve bir hedef çifti için metnin yazarının duruşunun (tutumunun) "Destekliyor" (Favor), "Desteklemiyor" (Against) ve "Duruş Yok" (Neither) etiketlerinden biri ile sinıflandırılması problemidir (S. Mohammad et al., 2016). Duruş tespitinde hedef olay, fikir, ürün, insan veya bir hareket olabilir. Hedef metin içerisinde açıça geçebilir veya geçmeyebilir.

Literatür incelemesi yapıldığında Türkçe dili için yapılan otomatik duruş tespiti çalışmalarının oldukça az olduğu görülmektedir. Bunun en önemli sebebi yeterli sayıda Türkçe duruş veri setinin bulunmamasıdır. Bu açığı kapatmak amacıyla, çalışmada 6 hedef için bir çevrimiçi forumdan toplanmış yorumlardan oluşan duruş etiketli bir veri seti hazırlanmıştır. ${ }^{2}$ Duruş tespiti çalışmalarında kullanılan mevcut veri setleri çoğunlukla mikroblog veya sosyal medya uygulamalarından toplanan verilerden oluşmaktadır. Bu sebeple veriler sınırlı sayıda karakterden oluşmakta ve yorum metni dışında platforma ait özelliklerde yapılan sinıflandırmada kullanılmaktadır.
Oluşturulan veri setinde karakter sınırlaması yapılmamıştır. Bundan dolayı veri seti çok sayıda kelimeden oluşan yorumları da içermektedir. Oluşturulan Türkçe veri seti üzerinde duruş tespit analizi için Destek Vektör Makineleri (DVM), Naive Bayes (NB), Rastgele Orman (RO), AdaBoost, XGBoost ve Evrişimli Sinir Ağı (ESA) yöntemleri kullanılmıştır. Metin madenciliği çalışmalarında en önemli kısım metinlerin iyi bir şekilde temsil edilmesidir. Bunun için makine öğrenmesi ve kolektif öğrenme yöntemlerinde sözcük torbası ve terim frekansı - ters doküman frekansı modelleri, ESA için ise kelime gömme modeli kullanılmıştır.

Çalışmanın devamında ikinci bölümde ilgili çalışmalar, üçüncü bölümde çalışmada kullanılan materyal ve metotlar, dördüncü bölümde araştırma sonuçları, beşinci bölümde sonuç ve gelecek çalışmalar sunulmuştur.

\section{2. İlgili Çalışmalar}

Literatür incelendiğinde, otomatik duruş tespiti ile ilgili çalışmanın amacına yönelik çeşitli tanımlara rastlanmaktadır. Bu tanımlar genel olarak 5 ana başlık altında toplanabilir. Bunlar şöyle sıralanabilir: Otomatik Duruş Tespiti (S. Mohammad et al., 2016), Çok Hedefli Duruş Tespiti (Sobhani et al., 2017), ÇaprazHedef Duruş Tespiti (C. Xu et al., 2018), Söylenti Duruş Tespiti (Zubiaga et al., 2018) ve Sahte Haber Duruş Tespiti (Fake News Challenge, 2017). Bu tanımlar arasında en yaygın kullanılanı, bu çalışmada da üzerinde durulacak olan Otomatik Duruş Tespitidir.

Duruş tespiti, yeni bir araştırma konusu olmasına rağmen literatür incelendiğinde bu konuda yapılmış çok sayıda çalışma olduğu görülmektedir. Bu çalışmalarda çeşitli yöntemler ile duruş sınıflandırmaları yapılmıştır. Çalışmalar incelendiğinde literatürde en çok kullanılan yöntem DVM'dir (Addawood et al., 2017; Aldayel \& Magdy, 2019; Dey et al., 2017; Küçük \& Can, 2018; Liu et al., 2016; S. M. Mohammad et al., 2017; Sobhani et al., 2015). DVM duruş sınıflandırmasında oldukça başarılı sonuçlar vermektedir. $\mathrm{Bu}$ sebeple baz yöntem olarak kullanılmaktadır. Sıklıkla kullanılan diğer yöntemler arasında NB (HaCohen-Kerner et al., 2017; Lai et al., 2016), ESA (Hercig et al., 2017; Zhang et al., 2017; Zhou et al., 2017), RO Algoritmas1 (Aker et al., 2017; Tsakalidis et al., 2018) yer almaktadır.

Yapılan duruş tespiti çalışmalarının çoğu İngilizce odaklıdır. $\mathrm{Bu}$ durum İngilizce dışındaki dillerde duruş sınıflarına ("Destekliyor", "Desteklemiyor", "Duruş Yok") göre etiketlenmiş yeterli sayıda derlemin (corpus) bulunmamasından kaynaklanmaktadır. İlgili literatür incelendiğinde Arapça, Katalanca, Çince, Çekçe, İtalyanca, Japonca, Rusça, İspanyolca gibi diğer dillerde de yeni yeni derlemler oluşturulmaya başlandığı görülmektedir. Bu veri setleri genellikle insanların sosyal medya platformlarındaki belli konularda paylaşımları kullanılarak oluşturulmaktadır.

Türkçe dili açısından incelendiğinde ise oldukça kısıtlı çalışma bulunduğu görülmüştür. Yapılan çalışmalarda Türkiye' deki popüler iki futbol kulübü hakkında tweetler toplanarak 2

\footnotetext{
${ }^{2}$ Çalışmada verilmiş olan sonuçların bu alanda çalışacak kişiler tarafından da doğrulanması amacıyla istenirse veri seti araştırmacılar ile paylaşılacaktır. Veri seti sorumlu yazara e-posta gönderilerek elde edilebilir.
} 
hedef (Galatasaray ve Fenerbahçe) 2 duruş sınıf etiketi (Favor ve Against) içeren bir veri seti oluşturularak DVM yöntemiyle sınıflandırma çalışması yapılmıştır (Küçük, 2017). Daha sonra veri sayısı arttırılmış ve varlık isim bilgisi eklenmiştir (Küçük \& Can, 2018, 2019).

\section{Materyal ve Metot}

$\mathrm{Bu}$ bölümde analiz edilen veri seti ve kullanılan metotlar hakkında bilgi verilmiştir.

\subsection{Veri Seti}

Türkçe duruş tespit analizi için çevrimiçi forumlardan toplanan yorumlar tercih edilmiştir. Veriler, veri kazıma yöntemi ile ekşi sözlük platformundan toplanmıştır. Bildiğimiz kadarıyla şimdiye kadarki en çok hedef-yorum ikilisine sahip yeni bir Türkçe duruş etiketli veri seti oluşturulmuştur. Veri seti 6 hedef için toplam 5031 yorum içermektedir. Bu hedefler Evden
Çalışma, Maske, E-kitap, Vegan, E-sigara ve Aşıdır. Veri setindeki yorumlar Türkiye' de yaşayan insanların rahatça anlayabileceği Türkçe ile yazılmış metinlerdir. Hedef, metin içinde açıkça bulunabilir veya bulunmayabilir. Veri seti, yazarların duruşunu açıkça, kinayeli veya dolaylı olarak bildirdikleri çeşitli yorumlardan oluşmaktadır. Her hedef için farklı olmak üzere her yorum üniversite dil bölümü mezunu 2 kişi (etiketleyeci) tarafından "Destekliyor" / "Desteklemiyor" / "Duruş Yok" etiketlerinden biri ile etiketlenmiştir. Her yorum için duruş etiketi doküman seviyesinde yapılmıştır. Tablo 1' de Türkçe Duruş Etiketli Veri Setinde yer alan örnek hedef-yorum çiftleri gösterilmiştir. Toplanan yorumlarda karakter sınırlaması yapılmamıştır. Bu sebeple yorumlar oldukça fazla sayıda kelime içerebilmektedir. Tablo 2' de her hedef için en kısa yorumun kelime sayıs1, yorumların ortalama kelime sayısı, en uzun yorumun kelime sayısı gösterilmiştir. Oluşturulan veri seti hedefler için dengesiz sınıf dağılımı göstermektedir. Şekil 1' de her hedef için sınıf etiket sayılarının dağılımları gösterilmiştir.

Tablo 1. Türkçe Duruş Etiketli Veri Seti Örnek Hedef-Yorum Çiftleri

\begin{tabular}{l|l|l}
\hline Hedef & Yorum & Duruş \\
\hline $\begin{array}{l}\text { Evden } \\
\text { Çalışma }\end{array}$ & $\begin{array}{l}\text { 2 gün işe gidememe durumunda kaldım rahatsızlığımdan dolayı ve çok net bir şekilde evden işi } \\
\text { yürtmenin çok daha zor ve stresli olduğunu söyleyebilirim. }\end{array}$ & "Desteklemiyor” \\
\hline E-kitap & $\begin{array}{l}\text { o kadar fiyasko ki e- kitap okuyucuları satış rekorları kırıyor. o fiyaskodan bir tane de ben } \\
\text { alabilir miyim? }\end{array}$ & "Destekliyor” \\
\hline
\end{tabular}

Tablo 2. Her Hedef Için Mecvut Yorumların Kelime Sayıları Bilgisi

\begin{tabular}{l|l|l|l}
\hline Hedef & En Az & Ortalama & En Çok \\
\hline Evden Çalışma & 1 & 63 & 876 \\
\hline Maske & 1 & 45 & 551 \\
\hline E-kitap & 1 & 80 & 1149 \\
\hline Vegan & 1 & 133 & 3902 \\
\hline E-sigara & 2 & 174 & 2182 \\
\hline Aşı & 1 & 90 & 3642 \\
\hline
\end{tabular}

Şekil 1. Her Hedef İçin Duruş Etiketli Sınıf Dă̆llım Bilgisi

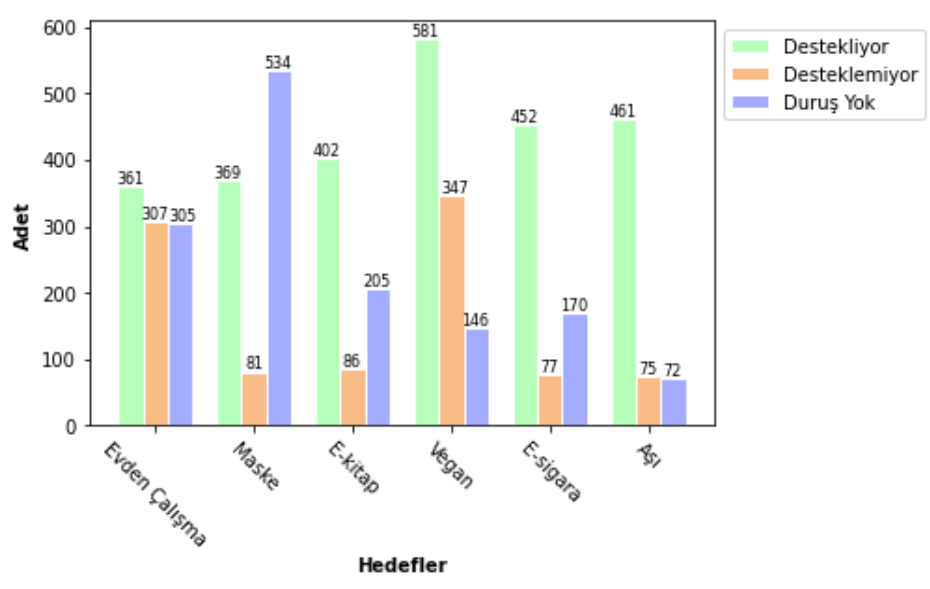

\footnotetext{
${ }^{3}$ https://eksisozluk.com/entry/104072994 (Erişim Tarihi: 13 Şubat 2021).

${ }^{4}$ https://eksisozluk.com/entry/37685827 (Erişim Tarihi: 13 Şubat 2021). 


\subsection{Veri Ön İşleme}

Sınıflandırma işlemi için öncelikle verinin temizlenmesi ve hazırlanması gerekmektedir. Bunun için ilk olarak metinde yer alan noktalama işaretleri, nümerik değerler, gereksiz terimler, özel karakterler, bağlantı adresleri, fazla boşluklar kaldırılmış ve tüm harfler küçük harfe dönüştürülmüş, yazım hataları düzeltilmiştir. Daha sonra kelimelerin gövdeleri çıkartılmıştır. Kelime gövdelerinin bulunmasında python programlama dili ile hazırlanmış TurkishMorphologicalAnalysis kütüphanesi kullanılmıştır (Yildiz et al., 2019).

Veri ön işlemlerinde genellikle gürültüyü engellemek için metin verilerinde durak kelimeleri kaldırılır. Fakat son yıllarda durak kelimelerini kullanmanın etkisi duygu sınıflandırma çalışmaları için tartışılmaktadır (Saif et al., 2014). Bu nedenle durak kelimelerinin duruş tespitinde etkisini görebilmek için veriler durak kelimeleriyle birlikte ve durak kelimeleri kaldırılmış olarak iki şekilde incelenmiş ve durak kelimeleri kullanılmasının model başarımını arttırdığı görülmüştür.

\subsection{Sinıflandırma}

Türkçe duruş etiketli veri seti üzerinde DVM, NB, ESA, RO, AdaBoost, XGBoost algoritmaları kullanılmıştır. Sınıflandırma algoritmaları doğrudan metin verileri ile çalışmaz. Metin verilerini sınıflandırma algoritmalarında kullanabilmek için sayısal verilere dönüştürülmesi gerekmektedir. Bu şekilde metin verilerinden oluşan yorumlar sınıflandırma algoritmalarında kullanılmak üzere sayısal matrislerle ifade edilir. Metinlerin sayısal olarak ifade edilebilmesi için bazı yöntemler kullanılmaktadır. Makine öğrenmesi ve kolektif öğrenme yaklaşımları için metinlerin temsil edilmesinde sözcük torbası ve Terim Frekans1-Ters Doküman Frekansı (TF-TDF) modelleri kullanılmıştır. Derin öğrenme yaklaşımında ise metin temsili için kelime gömme kullanılmıştır. Çalışmada kullanılan metin temsil yöntemleri aşağıda açıklanmıştır.

Sözcük Torbası (Bag of Words): Sözcük Torbası (ST) modeli bir metni nümerik olarak temsil etme yöntemlerinden biridir. S1klıkla kullanılan basit bir yöntemdir. Model için derlemde bulunan bütün tekil kelimelerin tutulduğu bir sözcük torbasına ihtiyaç vardır. Sözcük torbası oluşturulduktan sonra metindeki kelimelerin frekansları hesaplanır. Metin içinde yer alan kelimeler yer ve dilbilgileri gözardı edilerek temsil edilir.

Terim Frekansı - Ters Doküman Frekansı (Term Frequency - Inverse Document Frequency): Terim Frekans1 Ters Doküman Frekansı (TF-TDF), derlemdeki bir kelimenin metinlerdeki öneminin bir ölçüsüdür. Metinde kelimenin kullanılma sıklığı ve derlemde kullanılma sıklığı bilgilerinin birlikte kullanılması ile elde edilir. Bir kelimenin metinde sıklığ arttıkça TF-TDF değeri artarken derlemde kullanılma sıklığ arttıkça TF-TDF değeri azalır. $\mathrm{Bu}$ şekilde her metinde karşılaşılabilecek sıklıkla kullanılan kelimelerin değeri azaltılmış olur.

TF, belirli bir kelimenin belirli bir dokümandaki sıklığının dokümandaki toplam kelime sayısına oranı olarak ifade edilir. TF değeri, Denklem 1'de gösterildiği gibi hesaplanır. Burada belirli bir doküman için $d\left(K_{i}\right)$ i'ninci kelimenin dokümanda kaç defa kullanıldığını, $N$ dokümandaki toplam kelime sayını gösterir.

$$
\operatorname{TF}\left(K_{i}\right)=\frac{d\left(K_{i}\right)}{N}
$$

TDF, belirli bir kelimenin derlemde bulunduğu dokümanların sayısının toplam doküman sayısına oranının logaritması olarak ifade edilir. TDF değeri, Denklem 2'de gösterildiği gibi hesaplanır. Burada N $i$ 'ninci kelimenin bir derlemde kullanıldığ doküman sayısını, $\mathrm{M}$ ise derlemdeki toplam doküman sayısını gösterir.

$$
\operatorname{TDF}\left(K_{i}\right)=\log \frac{N}{M}
$$

TF-TDF ise TF*TDF olarak hesaplanır.

$$
\mathrm{TF}-\operatorname{TDF}\left(K_{i}\right)=\operatorname{TF}\left(K_{i}\right) * \operatorname{TDF}\left(K_{i}\right)
$$

Kelime Gömme (Embedding): Kelime gömme (KG) vektör gösterimin de çok büyük kelime dağarcığına sahip metinler 256 boyutlu, 512 boyutlu veya 1024 boyutlu kelime vektörleri ile temsil edilebilmektedir. Bu yaklaşımda her kelime için yoğun ve dağıtık bir gösterim kullanılır. Her kelime bir vektöre eşlenir ve vektör değerleri yapay sinir ağları benzeri bir algoritmalar ile işlenerek gerçel değerli kelime gömme vektörleri oluşturulur (Chollet, 2018). Bu yaklaşım göre; benzer şekilde kullanılan kelimeler benzer vektörlerle temsil edilirler.

\subsubsection{Naive Bayes}

Naive Bayes, bayes teoreminden yararlanılarak elde edilmiş metin verilerinin sınıflandırmasında çok sık kullanılan makine öğrenmesi algoritmalarından birisidir. Anlaşılabilir ve uygulaması kolay bir yöntemdir. Metin verileri ile çalışırken genellikle NB algoritmasının özelleştirilmiş bir hali olan Multinomial Naive Bayes (MNB) algoritması kullanılır. MNB algoritmasında metinler vektörleştirildikten sonra kelimelerin metinlerde kaç defa kullanıldığ 1 hesaplanır. Bu şekilde NB algoritmasındaki kelimenin metinde olup olmaması durumunun incelenmesine kıyasla metnin dahil olduğu sınıfa olan ilişkisi arttırılmaya çalışılmıştır. $S=\left\{s_{1}, s_{2}, \ldots, s_{i}\right\}$ sınıf etiketleri olmak üzere, derlemdeki $\mathrm{n}$ adet kelime için $K=\left\{k_{1}, k_{2}, \ldots, k_{n}\right\}$ olarak gösterilsin.

$$
P\left(s_{i} \mid m\right)=\frac{P\left(m \mid s_{i}\right) P\left(s_{i}\right)}{P(m)}
$$

Verilen bir $\mathrm{m}$ metninin $s_{i}$ sinıfina ait olma olasılı $\breve{g}_{1}$ bayes teoremine göre Denklem 5 ile hesaplanır.

$$
\begin{aligned}
s^{*}(m) & =\underset{\operatorname{argmax}}{\max }\left(s_{i}\right) P\left(s_{i} \mid m\right) \\
= & P\left(s_{i}\right) \prod_{t=1} P\left(k \mid s_{i}\right)^{o\left(k_{t}, m\right)}
\end{aligned}
$$

Denklem 5, m metni için en olası sınıfı gösteren denklemdir. Burada $o\left(k_{t}, m\right), \mathrm{m}$ metni içerisinde $k_{t}$ kelimesinin kaç defa geçtiğini gösterir. $\mathrm{Bu}$ şekilde belirli bir kelimenin bir sınıfa bulunma olasılığı frekans sayısı kadar güçlendirilmiş olur. Ek olarak $P\left(k_{t} \mid s_{i}\right)$ değeri Denklem 6' daki gibi hesaplanır. 


$$
P\left(k_{t} \mid s_{i}\right)=\frac{\sum_{m_{j} \in s_{i}} o\left(k_{t}, m_{j}\right)}{\sum_{t=1}^{n} \sum_{m_{j} \in s_{i}} o\left(k_{t}, m_{j}\right)}
$$

Eğer belirli kelime metin içinde yer almıyorsa Denklem 6' nın sonucu sifir olacaktır. Bu sebeple Denklem 5' in sonucu da sıfir olacaktır. Bu durumun önüne geçebilmek için Laplace dönüşümü yapılmaktadır. Bu şekilde Denklem 7’ de gösterilmiş̧ir.

$$
P\left(k_{t} \mid s_{i}\right)=\frac{1+\sum_{m_{j} \in s_{i}} o\left(k_{t}, m_{j}\right)}{n+\sum_{t=1}^{n} \sum_{m_{j} \in s_{i}} o\left(k_{t}, m_{j}\right)}
$$

\subsubsection{Destek Vektör Makineleri}

DVM, uzayın iki, üç veya çok boyutlu olmasına göre doğrusal, düzlemsel veya hiperdüzlem ayırma mekanizmaları ile uzaydaki verileri sınıflara ayırmayı sağlar. Doğrusal olarak ayrılabilen sınıflar için sıklıkla kullanılan bir yöntemdir. Doğrusal olarak ayrıştırılamayan sınıflardan oluşan verilerde çekirdek fonksiyonu yardımıyla verileri daha yüksek boyutta doğrusal olarak ayrıştırılabilen bir uzaya aktararak doğrusal olmayan verilerde de başarılı şekilde sınıflandırma yapabilir.

\subsubsection{Kolektif Öğrenme Yöntemleri}

Kolektif öğrenme yöntemleri, varyans ve önyargı hatalarını azaltarak daha gürbüz tahminleme modelleri üretmek amaciyla birden fazla zayıf sinıflandırıcının bir araya gelmesiyle oluşturulan meta algoritmalardır. Burada temel amaç tek bir sınıflandırıcı modelin elde ettiği tahminden daha yüksek tahmin doğruluğuna sahip model üretmektir. Paralel kolektif öğrenme teknikleri ve ardışık kolektif öğrenme yöntemleri olarak iki temel başlık altında özetlenebilir. Paralel kolektif öğrenme teknikleri, birbirinden bağımsız zayıf öğrenicilerin birbirine paralel olarak birleștirilmesiyle olușturulan öğrenme yöntemidir. Bagging yöntemi buna örnek olarak verilebilir.

(Breiman, 2001) tarafindan önerilen RO yöntemi, birbiriyle ilişkisiz çok sayıda karar ağacı modelinin birleşimine dayanan bir paralel kolektif öğrenme yöntemidir. Her örnek, sınıfının tahmin edilmesi için tüm ağaçlara aktarılır ve en çok oy alan sınıf, RO modelinin tahmini olarak belirlenir.

Ardışık kolektif öğrenme yöntemlerinde ise eğitim kümesindeki tüm örneklerin seçilme olasılıkları her eğitim iterasyonunda güncellenmektedir. Başlangıçta eğitim kümesindeki bütün örneklerin ağırlıkları aynıyken ilerleyen iterasyonlarda yanlış sınıflandırılan örneklerin ağırlıkları arttırılarak sınıflandırıcının yanlış sınıflandırılmış örneklere odaklanması sağlanıp, model başarım oranı arttırılmaktadır. (Freund \& Schapire, 1997) tarafindan geliştirilen Adaboost algoritması ilk geliştirilen boosting algoritmalarındandır.

Diğer bir boosting yöntemi olan Gradyan Boosting, modeldeki zayıf regresyon ağaçlarına yinelemeli bir şekilde yeni ağaçlar ekleyerek regresyon ağaçları topluluğu oluşturan ve bunu da türevi alınabilen bir kayıp fonksiyonunun eniyilenmesi sayesinde iyileştiren bir yöntemdir (Natekin \& Knoll, 2013). Bu yöntemin en yeni gerçeklemelerinden biri XGBoost algoritmasıdır. Boosting, Regularized boosting ve Stokastik boosting tekniklerini gerçekleyen XGBoost algoritması işlem süresini azaltarak ve bellek kaynaklarının optimum kullanılmasını sağlamaktadır (Chen \& Guestrin, 2016). Ayrıca düzenlileştirme (regularization) parametrelerini ayarlama özelliği sayesinde modelin aşırı uyum (overfitting) göstermesini engellemekte ve modeldeki ağaçların karmaşıklığını kontrol ederek yüksek başarı oranı elde etmektedir.

\subsubsection{Evriş̧imli Sinir A}

ESA, günümüzde oldukça başarılı sonuçlar veren önemli derin öğrenme yapılarından biridir. Çeşitli doğal dil işleme problemlerinde de kullanılmaktadır. ESA mimarisi temelde girdi katmanında bir matris alan, evrişim katmanı, ortaklama katmanı ve tam bağlantı katmanı olmak üzere dört kısımdan oluşur. Evrişim katmanında girdiler farklı filtrelerle evrişim işleminden geçirilerek öznitelik haritaları çıkartılır. Ortaklama katmanında, elde edilen öznitelik haritalarının boyutları azaltılır. Tam bağlantı katmanında ise tüm nöronlar kendinden önceki katmanın tüm çıktılarına bağlı bir çıkış değeri üretir.

\subsection{Model Performans Ölçütü}

Model performanslarını karşılaştırmak için karışıklık matrisinden (Şekil 2) elde edilen doğruluk oranı, kesinlik, anma ölçümleri kullanılmaktadır. Ancak, veri setindeki sınıf dengesizliğinin sınıflandırma performans ölçütleri üzerindeki etkisi büyüktür ve gözlem sayısı olarak baskın durumdaki sınıf doğruluk oranı, kesinlik, anma ölçümlerini olumsuz olarak etkilemektedir. Bu yüzden, dengesiz veri setleri üzerinde yapılan çalışmalarda model performanslarını karşılaştırmak için genellikle kesinlik ve anma ölçümlerinin harmonik ortalaması olan F1 Ölçümü yaygın olarak kullanılmaktadır.

Şekil 2. Karışılklı Matrisi

\begin{tabular}{|c|c|c|c|}
\hline \multicolumn{2}{|l|}{} & \multicolumn{2}{c|}{ Gerçek } \\
\hline \multirow{2}{*}{} & & Pozitif & Negatif \\
\cline { 2 - 4 } & Pozitif & $\begin{array}{c}\text { Doğru Pozitif } \\
\text { (DP) }\end{array}$ & $\begin{array}{c}\text { Yanlış Pozitif } \\
\text { (YP) }\end{array}$ \\
\cline { 2 - 4 }$: 0$ & Negatif & $\begin{array}{c}\text { Yanlış Negatif } \\
\text { (YN) }\end{array}$ & $\begin{array}{c}\text { Doğru Negatif } \\
\text { (DN) }\end{array}$ \\
\hline
\end{tabular}

$$
\begin{gathered}
\text { Anma }(\text { Recall })=\frac{\text { Doğru Pozitif }}{\text { Doğru Pozitif }+ \text { Yalnış Negatif }} \\
\text { Kesinlik }(\text { Precision })=\frac{\text { Doğru Pozitif }}{\text { Doğru Pozitif }+ \text { Yalnış Pozitif }} \\
F 1 \text { Ölçüm }=\frac{\text { Kesinlik } * \text { Anma }}{\text { Kesinlik }+ \text { Anma }}
\end{gathered}
$$

Doğruluk ve F1 Ölçüm ölçümleri literatürde popüler olmasına rağmen dengesiz veri kümelerinde, yanıltıcı sonuçlar doğurabilmektedir. (Luque et al., 2019), sınıflandırma hatalarının da dikkate alınması gerektiği durumlarda Matthews Korelasyon Katsayısının (MKK) (Matthews, 1975) performans ölçütü olarak kullanılmasının en iyi seçim olduğunu göstermişlerdir. MKK hesaplanırken, karışıklık matrisindeki denge oranlar (GP, GN, YP, YN) hesaba katıldığından, MKK F1 Ölçümünden daha 
bilgilendiricidir. Denklem 11'de görüldüğü üzere MKK değeri yalnızca model hem negatif hem de pozitif öğeler üzerinde iyi performans gösteriyorsa yüksektir, aksi taktirde sıfira yakın değerler alır. (Chicco \& Jurman, 2020)'deki çalışmalarında sınıf dengesizliğinin olduğu veri kümelerinde MKK ölçümü kullanılmasının avantajlarını göstermişlerdir.

$$
M K K=\frac{D P * D N-Y P * Y N}{\sqrt{(D P+Y P)(D P+Y N)(D N+Y P)(D N+Y N)}}
$$

-1 ve +1 arasında bir değer alan MKK katsayısı, +1 değerini aldığında model mükemmel bir tahminde bulunur, 0 değerinde modelin tahmini rastgele tahminlerden daha iyi değildir. -1 değerini aldığında ise model tahmini ile gözlem arasındaki toplam uyuşmazlığ1 gösterir. Şekil 1' de görüldüğü üzere veri setimizdeki duruş etiketleri dengesiz bir yapı göstermektedir. $\mathrm{Bu}$ yüzden model performans başarım sıralamasını MKK ölçümü ve F1 ölçümlerini birlikte göz önünde bulundurarak yaptık.

\subsection{Entegre Gradyanlar Yöntemi}

Entegre Gradyanlar (EG), gradyanlara dayalı bir makine öğrenmesi modelinde girdinin her bir özelliğine bir önem değeri atamayı amaçlayan bir yöntemdir (Sundararajan et al., 2017). EG, sınıflandırma ve regresyon modelleri için kullanılabilir.
$\mathrm{EG}, F: R^{n} \rightarrow[0,1]$ bir derin ağ1 fonksiyonunda $x^{\prime} \in R^{n}$ ise temel girdisinden $x \in R^{n}$ mevcut girdisine kadarki bütün noktalardaki gradyanlarının toplamıdır. EG hesaplanırken metin modellerinde temel girdi için genellikle sıfır gömme vektörü kullanılır. Mevcut bir $x$ girdisinin temel $x^{\prime}$ girdisine kadar $i$. Boyut boyunca entegre gradyanı aşağıdaki gibi ifade edilir (Sundararajan et al., 2017).

$$
E G_{i}\left(x, x^{\prime}\right)=\left(x_{i}-x_{i}^{\prime}\right) \int_{\theta=0}^{1} \frac{\partial F\left(x^{\prime}+\theta\left(x-x^{\prime}\right)\right)}{\partial x_{i}} d \theta
$$

\section{Araştırma Sonuçları ve Tartışma}

\subsection{Deneysel Sonuçlar}

Oluşturulan veri seti üzerinde makine öğrenmesi, kolektif öğrenme yöntemleri ve evrişimli sinir ağı modeli ile performans ölçümleri yapılmıştır. Veri temsili için makine öğrenmesi ve kolektif öğrenme yöntemlerinde sözcük torbası ve kelime seviyesinde TF-TDF, derin öğrenme yönteminde ise kelime gömme modeli kullanılmıştır. Makine öğrenmesi ve kolektif öğrenme modellerinde 5-kat çapraz geçerleme uygulanmıştır. Elde edilen sonuçlar Tablo 3' te gösterilmiştir.

Tablo 3. Türkçe Duruş Etiketli Veri Seti Üzerinde Yapılan Duruş Sınıflandırması Sonuçları*

\begin{tabular}{l|c|c|c|c|c|c|c|c|c|c|c|c}
\hline \multicolumn{1}{c|}{ Hedef } & Evden Çalışma & \multicolumn{2}{c|}{ Maske } & \multicolumn{2}{c|}{ E-kitap } & \multicolumn{2}{c|}{ Vegan } & \multicolumn{2}{c|}{ E-sigara } & \multicolumn{2}{c}{ Aşl } \\
\hline \multicolumn{1}{c|}{ Yöntem/Öznitelik } & F1 Ölçüm & MKK & F1 Ölçüm & MKK & F1 Ölçüm & MKK & F1 Ölçüm & MKK & F1 Ölçüm & MKK & F1 Ölçüm & MKK \\
\hline NB/ST & 0,46 & 0,24 & 0,61 & 0,31 & 0,49 & 0,11 & 0,49 & 0,13 & 0,56 & 0,11 & 0,70 & 0,21 \\
\hline NB/TF-TDF & 0,32 & 0,18 & 0,60 & 0,31 & 0,43 & 0,02 & 0,38 & $-0,01$ & 0,52 & 0,00 & 0,66 & 0,00 \\
\hline DVM/ST & 0,52 & $0,28^{3}$ & 0,59 & 0,26 & 0,55 & $0,22^{\mathbf{2}}$ & 0,53 & $0,22^{3}$ & 0,65 & $0,31^{\mathbf{3}}$ & 0,76 & $0,39^{\mathbf{3}}$ \\
\hline DVM/TF-TDF & 0,53 & $0,30^{\mathbf{2}}$ & 0,62 & $0,33^{\mathbf{3}}$ & 0,53 & 0,18 & 0,50 & 0,16 & 0,62 & 0,25 & $\mathbf{0 , 7 6}$ & $0,43^{\mathbf{1}}$ \\
\hline AdaBoost/ST & 0,51 & 0,27 & 0,57 & 0,23 & 0,55 & $0,22^{\mathbf{3}}$ & 0,52 & 0,18 & 0,64 & $0,33^{\mathbf{2}}$ & 0,75 & 0,34 \\
\hline AdaBoost/TF-TDF & 0,44 & 0,18 & 0,55 & 0,20 & 0,55 & 0,20 & 0,48 & 0,13 & 0,63 & 0,28 & 0,75 & 0,34 \\
\hline XGBoost/ST & $\mathbf{0 , 5 4}$ & $0,31^{\mathbf{1}}$ & $\mathbf{0 , 6 4}$ & $0,37^{\mathbf{1}}$ & 0,54 & 0,18 & 0,51 & 0,20 & 0,65 & 0,30 & 0,76 & $0,39^{\mathbf{2}}$ \\
\hline XGBoost/TF-TDF & 0,19 & 0,01 & 0,38 & 0,01 & 0,43 & 0,01 & 0,28 & 0,02 & 0,52 & 0,01 & 0,68 & 0,13 \\
\hline RO/ST & 0,50 & 0,27 & 0,61 & 0,32 & 0,55 & 0,20 & 0,51 & 0,21 & 0,65 & $0,31^{\mathbf{3}}$ & 0,69 & 0,18 \\
\hline RO/TF-TDF & 0,49 & 0,26 & 0,61 & $0,33^{\mathbf{2}}$ & 0,54 & 0,19 & 0,51 & $0,22^{2}$ & 0,64 & 0,28 & 0,69 & 0,19 \\
\hline ESA/KG & 0,52 & 0,27 & 0,60 & $0,33^{\mathbf{3}}$ & $\mathbf{0 , 5 5}$ & $0,24^{\mathbf{1}}$ & $\mathbf{0 , 5 6}$ & $0,25^{\mathbf{1}}$ & $\mathbf{0 , 6 2}$ & $0,36^{\mathbf{1}}$ & 0,75 & 0,33 \\
\hline
\end{tabular}

${ }^{*}$ MKK değerlerindeki üst indis sıralama göstermektedir.

Yapılan deneylerde yüksek F1 Ölçüm değeri elde eden bazı modeller karışıklık matrisi incelendiğinde tüm sınıfları ayırt etmede başarılı olmadığı görülmüştür. $\mathrm{Bu}$ durum veri kümesindeki sinıfların dengesiz dağılımından kaynaklanmaktadır. Bu sebeple MKK değeri ağırlıklı olmak üzere model başarımları değerlendirilmiştir. Özellikle E-sigara hedefi için alınan sonuçlar incelendiğinde en yüksek F1 Ölçümü sözcük torbası metin temsili ile XGBoost, RO ve DVM modelleri ile elde edilmiş olmasına rağmen MKK değeri ile birlikte başarımı en yüksek model ESA olarak belirlenmiştir.

Tablo 3' te verilen sonuçlar incelendiğinde Evden Çalışma ve Maske hedefleri için sözcük torbası metin temsili ile XGBoost modeli, E-kitap, Vegan ve E-sigara hedefleri için ESA modeli, Aş1 hedefi için TF-TDF metin temsili ile DVM modeli en yüksek başarımları elde etmiştir. Oluşturulan veri seti üzerinde duruş tespit analizi için XGBoost ve ESA modellerinin daha başarılı olduğu görülmüştür.
Çalışmada kullanılan veri kümesinde karakter sınırlaması yapılmamıştır. Tablo 2'de de görüldüğü üzere yazarlar duruşlarını uzun yorumlar yazarak ifade etmektedirler. Bazı hedefleri için yapılan yorumların, çok uzun yazıldığı, yorumlar da hedef dışındaki konulardan bahsedildiği hatta diğer duruş sınıflarını da destekleyecek şekildeki ifadelerin kullanıldığı görülmüştür. $\mathrm{Bu}$ durum her hedef için oluşturulan modellerin girdi vektörlerinde kullanılan tekil kelime sayısının farklı olmasına, dolayısıyla birçok elemanı sıfır olan büyük girdi vektörleri kullanan modeller oluşturulmasına neden olmuştur. Örneğin Vegan hedefi için yapılan yorumlarda 10526 tekil kelime kullanılırken Maske hedefi için 4343 tane tekil kelime kullanılmıştır. Bu yüzden en yüksek başarım gösteren modeller, her hedef için farklılık göstermektedir. 


\subsection{Entegre Gradyanlar Yöntemi ile Girdi Verilerinin Yorumlanması}

Günümüzde yapay öğrenme modelleri ile başarılı sonuçlar elde edilmektedir. Modellerin açıklanabilir ve yorumlanabilir olması sonuçların değerlendirilebilmesi açısından oldukça önemlidir. Bu sebep ile bu bölümde EG yöntemi Türkçe Duruş Etiketli Veri Seti üzerinde eğitilmiş bir ESA modeline uygulanmıştır. ESA modeli 250 filtreli bir evrişism katmanı, global maksimum hesaplaması yapan bir ortaklama katmanı ve 250 düğümden oluşan bir gizli katmandan oluşmaktadır. Metin sınıflandırma modellerinde, EG, girdi cümlesindeki her kelime için bir önem değeri hesaplar. Oluşturulan ESA modeli için girdilerin her bir özniteliğinin model tahminine katkısı hesaplanmıştır. Girdi verisinde yer alan her kelimenin model tahminine sağladığı katkı görselleştirilerek sunulmuştur. $\mathrm{Bu}$ görselleştirme yorumlardaki kelimelerin katkılarına göre renklendirilerek yapılmıştır. Modelin kararına olumlu katk1 sağlayan kelimeler yeşil, olumsuz katkı sağlayan kelimeler pembe ve katkısı olmayan kelimeler gri olarak renklendirilmiştir. Renklerin yoğunluğunun artması kelimenin model tahminine yaptığı katkının arttığı anlamına gelmektedir. Şekil 3' de EG yöntemi ile girdi verilerinin model tahminine katkısı görsel olarak gösterilmiştir.

EG yöntemi ile girdi verilerinde yer alan kelimeler incelendiğinde model tahminlerinde bazı hedefler için bazı kelimelerin katkı sağladığı görülmüştür. Aşı ve E-sigara hedefleri için yapılan yorumlarda bağlaçların kullanılması modelin "Duruş Yok” tahmini yapmasına katkı sağlamıştır. E-kitap hedefi için 'e', 'elektronik', 'amazon', 'internet' gibi kelimeler modelin "Destekliyor” duruş tahmini yapmasına katkı sağlarken E-sigara hedefi için 'cihaz', 'nikotin', 'elektronik', 'likit', 'normal', 'değil' kelimeleri, modelin "Destekliyor" duruş tahmini yapmasına katkı sağlamıştır. Benzer şekilde Evden Çalışma hedefi için 'süre', 'mesai', 'daha', 'zor' kelimeleri modelin "Desteklemiyor" duruş tahmini yapmasına katkı sağlarken, Maske hedefi için 'takmak', 'çünkü', 'korumak', 'hasta' kelimeleri modelin 'Destekliyor' duruş tahmini yapması için katkı sağlamıştır. Vegan hedefi için ayırt edici kelime grupları elde edilememiştir. Kelimelerin tek başına katkılarından ziyade girdi verisinde birlikte bulundukları kelimelerle tahmine daha çok etki ettikleri görülmüştür. Art arda yer alan bazı ikili ve üçlü kelime gruplarının model tahminine daha çok katkı sağladığ 1 gözlemlenmiştir.

Şekil 3. EG Yöntemi ile Girdi Verilerinin Model Tahminine Katkılarının Görselleştirilmesi. ${ }^{5}$

$\begin{array}{ll}\begin{array}{l}\text { Hedef } \\ \text { Evden Çalışma }\end{array} & \text { Yorum } \\ & \text { masten çalışmaktan kesinlikle daha zor * } \\ \text { Maske } & \begin{array}{l}\text { bilinmediği kalabalık yerlerde herkesin takması daha iyidir herkes takarsa anlamı vardır } \\ \text { eldiven de ancak yarim saat korur sonra çıartmak gerekir ve eldivenli iken ele yüze } \\ \text { dokunmamak gerekir ** }\end{array} \\ \text { e-kitap } & \text { kitaplardan kurtulabileceğinizi sanmayın *** }\end{array}$

Hedef

ofisten çalișmaktan kesinlikle daha zor * bilinmediği kalabalık yerlerde herkesin takması daha iyidir herkes takarsa anlamı vardır dokunmamak gerekir **

e-kitap
Tahmin

Desteklemiyor

Destekliyor

Duruş Yok

\section{Sonuç ve Gelecek Çalışmalar}

Duruş tespit analizi, metin yazarının bir hedefe yönelik duruşunun otomatik olarak bulunmasını amaçlayan bir çalışma konusudur. $\mathrm{Bu}$ çalışmanın en büyük katkısı Türkçe dilinde kapsamlı bir duruş etiketli veri setinin oluşturulmuş olmasıdır. $\mathrm{Bu}$ veri seti bildiğimiz kadarıyla Türkçe dili için en büyük duruş etiketli veri setidir. Bu veri seti üzerinde NB, DVM, Kolektif Öğrenme ve ESA yöntemleri kullanılarak duruş analizi çalışması yapılmıştır. Yapılan deneyler sonucunda hedef bazlı farklılıklar olmakla beraber en yüksek başarımlar XGBoost ve Evrişimli Sinir Ağı modelleri ile elde edilmiştir. Deney sonuçları literatürdeki mevcut duruş tespiti çalışmalarında elde edilen sonuçlara benzerdir. Durak kelimelerinin kullanımı modellerin performansını yükseltmiştir. Veri setinde çok uzun yorumların bulunması ve sınıfların dengesiz dağılımı modellerin performansını olumsuz etkilemiştir. Bu sebeple oluşturulan veri setinin genişletilmesi amaçlanmaktadır. Kullandığımız üç metin temsili de kelimelerin cümle içindeki yer bilgisini göz ard1 etmektedir. Bu bilginin duruş tespiti için önemli olabileceği düşünülmektedir. Bu sebeple, Türkçe Bert gibi önceden eğitilmiş dil modelleri ve dikkat mekanizmalı derin bellek ağları gibi yapılar kullanılarak daha başarılı modeller geliştirilmesi planlanmaktadir.

EG yöntemi ile ESA modelinde girdilerin özniteliklerinin model tahminine katkıları incelenmiştir. Yorumdaki kelimelerin duruş tahmini için modele etkileri görselleştirilerek yorumlanmıştır. Bunun sonucunda bazı hedefler için bazı kelimelerin model tahminine yüksek katkı yaptıkları görülmüştür. Fakat bu kelimeler Türkçe dili için hedef bazlı bir duruş sözlüğü oluşturulmasına yeterli olmamıştır. İlerleyen zamanlarda hedef bazlı Türkçe duruş sözlükleri oluşturularak Türkçe duruş tespit başarımının arttırılması amaçlanmaktadır.

\section{Teșekkür}

Türkçe Duruş Veri Setinin hazırlanması sırasında metinlerin "Destekliyor" / "Desteklemiyor" / "Duruş Yok" olarak etiketlemesindeki yardımlarından dolayı Starlang Yazılım ve Danışmanlık Sanayi ve Ticaret Ltd. çalışanları Sayın Büşra

\footnotetext{
5 *https://eksisozluk.com/entry/109334587 (Erişim Tarihi: 13 Şubat 2021).

** https://eksisozluk.com/entry/103795301 (Erişim Tarihi: 13 Şubat 2021).

*** https://eksisozluk.com/entry/26973184 (Erişim Tarihi: 13 Şubat 2021).
} 
Marşan, Bilge Nas Arıcan, Neslihan Kara, Neslihan Cesur, Ezgi Sanıyar, Oğuzhan Kuyrukçu, Aslı Kuzgun, Merve Özçelik’e yazarlar olarak teşekkürlerimizi sunarız.

\section{Kaynakça}

Addawood, A., Schneider, J., \& Bashir, M. (2017). Stance Classification of Twitter Debates: The Encryption Debate as A Use Case. Proceedings of the 8th International Conference on Social Media \&amp; Society. https://doi.org/10.1145/3097286.3097288

Aker, A., Derczynski, L., \& Bontcheva, K. (2017). Simple open stance classification for rumour analysis. ArXiv Preprint ArXiv:1708.05286.

Aldayel, A., \& Magdy, W. (2019). Your stance is exposed! analysing possible factors for stance detection on social media. Proceedings of the ACM on Human-Computer Interaction, 3(CSCW), 1-20.

Breiman, L. (2001). Random forests. Machine Learning, 45(1), 5-32.

Chen, T., \& Guestrin, C. (2016). Xgboost: A scalable tree boosting system. Proceedings of the 22nd Acm Sigkdd International Conference on Knowledge Discovery and Data Mining, 785-794.

Chicco, D., \& Jurman, G. (2020). The advantages of the Matthews correlation coefficient (MCC) over F1 score and accuracy in binary classification evaluation. $B M C$ Genomics, 21(1), 6 .

Chollet, F. (2018). Deep Learning mit Python und Keras: Das Praxis-Handbuch vom Entwickler der Keras-Bibliothek (pp. 180-195). MITP-Verlags GmbH \& Co. KG.

Dey, K., Shrivastava, R., \& Kaushik, S. (2017). Twitter stance detection-A subjectivity and sentiment polarity inspired two-phase approach. 2017 IEEE International Conference on Data Mining Workshops (ICDMW), 365-372.

Du Bois, J. W. (2007). The stance triangle. Stancetaking in Discourse: Subjectivity, Evaluation, Interaction, 164(3), 139-182.

Fake News Challenge. (2017). http://www.fakenewschallenge.org/

Freund, Y., \& Schapire, R. E. (1997). A decision-theoretic generalization of on-line learning and an application to boosting. Journal of Computer and System Sciences, 55(1), 119-139.

HaCohen-Kerner, Y., Ido, Z., \& Ya'akobov, R. (2017). Stance classification of tweets using skip char ngrams. Joint European Conference on Machine Learning and Knowledge Discovery in Databases, 266-278.

Hercig, T., Krejzl, P., Hourová, B., Steinberger, J., \& Lenc, L. (2017). Detecting Stance in Czech News Commentaries. ITAT, 176-180.

Küçük, D. (2017). Stance Detection in Turkish Tweets. ArXiv Preprint ArXiv:1706.06894.

Küçük, D., \& Can, F. (2018). Stance Detection on Tweets: An SVM-based Approach. ArXiv Preprint ArXiv:1803.08910.

Küçük, D., \& Can, F. (2019). A Tweet Dataset Annotated for Named Entity Recognition and Stance Detection. ArXiv Preprint ArXiv:1901.04787.

Lai, M., Far '’ias, D. I. H., Patti, V., \& Rosso, P. (2016). Friends and enemies of clinton and trump: using context for detecting stance in political tweets. Mexican International Conference on Artificial Intelligence, 155-168.

Liu, C., Li, W., Demarest, B., Chen, Y., Couture, S., Dakota, D.,
Haduong, N., Kaufman, N., Lamont, A., Pancholi, M., \& others. (2016). Iucl at semeval-2016 task 6: An ensemble model for stance detection in twitter. Proceedings of the 10th International Workshop on Semantic Evaluation (SemEval-2016), 394-400.

Luque, A., Carrasco, A., Mart'’in, A., \& de las Heras, A. (2019). The impact of class imbalance in classification performance metrics based on the binary confusion matrix. Pattern Recognition, 91, 216-231.

Matthews, B. W. (1975). Comparison of the predicted and observed secondary structure of T4 phage lysozyme. Biochimica et Biophysica Acta (BBA)-Protein Structure, 405(2), 442-451.

Mohammad, S., Kiritchenko, S., Sobhani, P., Zhu, X., \& Cherry, C. (2016). $\{\mathrm{S}\} \mathrm{em}\{\mathrm{E}\}$ val-2016 Task 6: Detecting Stance in Tweets. Proceedings of the 10th International Workshop on Semantic Evaluation (\{S\}em\{E\}val-2016), 31-41. https://doi.org/10.18653/v1/S16-1003

Mohammad, S. M., Sobhani, P., \& Kiritchenko, S. (2017). Stance and sentiment in tweets. ACM Transactions on Internet Technology (TOIT), 17(3), 1-23.

Natekin, A., \& Knoll, A. (2013). Gradient boosting machines, a tutorial. Frontiers in Neurorobotics, 7, 21.

Saif, H., Fernández, M., He, Y., \& Alani, H. (2014). On stopwords, filtering and data sparsity for sentiment analysis of twitter.

Sobhani, P., Inkpen, D., \& Matwin, S. (2015). From argumentation mining to stance classification. Proceedings of the 2nd Workshop on Argumentation Mining, 67-77.

Sobhani, P., Inkpen, D., \& Zhu, X. (2017). A Dataset for MultiTarget Stance Detection. Proceedings of the 15th Conference of the $\{E\}$ uropean Chapter of the Association for Computational Linguistics: Volume 2, Short Papers, 551-557. https://www.aclweb.org/anthology/E17-2088

Sundararajan, M., Taly, A., \& Yan, Q. (2017). Axiomatic attribution for deep networks. ArXiv Preprint ArXiv:1703.01365.

Taulé, M., Mart'`i, M. A., Rangel, F. M., Rosso, P., Bosco, C., Patti, V., \& others. (2017). Overview of the task on stance and gender detection in tweets on Catalan independence at IberEval 2017. 2nd Workshop on Evaluation of Human Language Technologies for Iberian Languages, IberEval 2017, 1881, 157-177.

Tsakalidis, A., Aletras, N., Cristea, A. I., \& Liakata, M. (2018). Nowcasting the stance of social media users in a sudden vote: The case of the Greek Referendum. Proceedings of the 27th ACM International Conference on Information and Knowledge Management, 367-376.

Xu, C., Paris, C., Nepal, S., \& Sparks, R. (2018). Cross-Target Stance Classification with Self-Attention Networks.

Xu, R., Zhou, Y., Wu, D., Gui, L., Du, J., \& Xue, Y. (2016). Overview of nlpcc shared task 4: Stance detection in chinese microblogs. In Natural Language Understanding and Intelligent Applications (pp. 907-916). Springer.

Yildiz, O. T., Avar, B., \& Ercan, G. (2019). An Open, Extendible, and Fast $\{\mathrm{T}\}$ urkish Morphological Analyzer. Proceedings of the International Conference on Recent Advances in Natural Language Processing (RANLP 2019), 1364-1372. https://doi.org/10.26615/978-954-452-0564_156

Zhang, S., Qiu, L., Chen, F., Zhang, W., Yu, Y., \& Elhadad, N. (2017). We make choices we think are going to save us: Debate and stance identification for online breast cancer 
CAM discussions. Proceedings of the 26th International Conference on World Wide Web Companion, 1073-1081.

Zhou, Y., Cristea, A. I., \& Shi, L. (2017). Connecting targets to tweets: Semantic attention-based model for target-specific stance detection. International Conference on Web
Information Systems Engineering, 18-32.

Zubiaga, A., Aker, A., Bontcheva, K., Liakata, M., \& Procter, R. (2018). Detection and Resolution of Rumours in Social Media: A Survey. ACM Comput. Surv., 51(2). https://doi.org/10.1145/3161603 